\title{
A Comparative Evaluation of the Effectiveness of Three Different Modalities in Occluding Dentinal Tubules: An In Vitro Study
}

\author{
Anu A George ${ }^{1}$, Alex M Muruppel ${ }^{2}$, Sudeep $\mathrm{S}^{3}$, Dinesh $\mathrm{N}^{4}$, Sandeep Lal ${ }^{5}$
}

\begin{abstract}
Aim: This in vitro study was designed to evaluate and compare the effectiveness of a dentifrice containing $8 \%$ arginine and calcium carbonate, diode laser $(810 \mathrm{~nm})$ and the combined use of diode laser $(810 \mathrm{~nm})$ and the same dentifrice in occluding dentinal tubules.

Materials and methods: Forty sectioned dentine discs were observed in this study. The Samples were randomly divided into 4 groups. In group A, a dentifrice containing arginine and calcium carbonate was applied. In group B, the specimens were subjected to diode laser (810 $\mathrm{nm}$ ) irradiation. In group C, the same dentifrice was applied and the specimens were subjected to diode laser ( $810 \mathrm{~nm}$ ) treatment. Group D was left untreated and served as the control. The specimens were observed under the scanning electron microscope. Then the photomicrographs of each specimen were taken which were uploaded into Photoshop $7^{\circledR}$, and the diameters of the dentinal tubules of each specimen were measured and the data were analyzed statistically.
\end{abstract}

Results: The overall comparison between different treatment modalities using one-way analysis of variance (ANOVA) and multiple comparisons of two modalities assessed using post hoc Tukey method revealed that there is a highly significant difference $(p$ value $=0.0001)$ in the dentinal tubule diameter and rate of occlusion in different treatment modalities.

Conclusion: The study concluded that all three treatment modalities caused significant occlusion of dentinal tubules. The combined use of desensitizing toothpaste and diode laser $(810 \mathrm{~nm})$ is the most effective, then comes the diode laser $(810 \mathrm{~nm})$ alone and finally the desensitizing toothpaste alone.

Clinical significance: This study suggests an effective treatment of dentinal hypersensitivity using diode laser and desensitizing toothpaste. Keywords: Dentinal hypersensitivity, Desensitizing toothpaste, Diode laser, Tubule occlusion

The Journal of Contemporary Dental Practice (2019): 10.5005/jp-journals-10024-2538

\section{INTRODUCTION}

D entinal hypersensitivity is a common, clinical condition that causes discomfort and sometimes severe pain, affecting $4-73 \%$ of the adult population in clinical dentistry. ${ }^{1-4}$ It is caused by exposure of spots of dentinal tubules to the oral environment. ${ }^{5-12}$

It is typically experienced in an age range from 20-49 years, with a peak incidence between 30-39years. The buccal cervical regions of the permanent teeth are the most commonly affected surfaces, with canine, premolar and incisor teeth being more frequently affected than molars. ${ }^{5}$ This problem is characterized by a short, sharp, and severe pain arising from exposed dentin in response to stimuli, typically thermal, evaporative, tactile, osmotic or chemical, ceasing after their removal., ${ }^{1,13}$

Dentinal sensitivity can be a great concern to the patient and dentist. ${ }^{2-4}$ Furthermore, there is no unanimity of opinion about solutions proposed to reduce dentinal sensitivity.

Conventional therapy for hypersensitive teeth is based on using topically applied desensitizing agents, either professionally or at home. However, most treatments are not very effective and last for only a short while. ' Conventional desensitizing agents (professional pastes, kinds of toothpaste, mouthwashes) aim to obliterate the exposed dentinal tubules. ${ }^{14-21}$

Induction of natural mineral formation by in situ - ew technologies, such as the Pro-Argin technology and NovaMin bioactive glass, are believed to bind to the exposed dentin surface and within the openings of the dentin tubules to mediate the formation of biological mineral. ${ }^{5,22,23}$

Laser desensitization is also a novel and efficient alternative for the immediate treatment of dentinal hypersensitivity. ${ }^{24-28}$ Lasers are being investigated for the treatment of hypersensitivity
${ }^{1}$ Department of Prosthodontics, KMCT Dental College, Kozhikode, Kerala, India

${ }^{2}$ Department of Implantology, Azeezia College of Dental Science and Research, Kollam, Kerala, India

3,4 Department of Prosthodontics, PMS College of Dental Science and Research, Thiruvananthapuram, Kerala, India

${ }^{5}$ Taluk Head Quarters Hospital, Kerala Health Services, Wayanad, Kerala, India Corresponding Author: Anu A George, Department of Prosthodontics, KMCT Dental College, Kozhikode, Kerala, India, Phone: +919446562968, e-mail: anusaara@gmail.com

How to cite this article: George AA, Muruppel AM, Sudeep S, Dinesh N, Lal S. A Comparative Evaluation of the Effectiveness of Three Different Modalities in Occluding Dentinal Tubules: An In Vitro Study. J Contemp Dent Pract 2019;20(4):454-459.

Source of support: Nil

Conflict of interest: None

as a monotherapy or in combination with desensitizing agents incorporated in toothpaste in regular use by patients. ${ }^{17,29-31}$

Presently there is no standard protocol of treatment for the same. This study evaluates the effectiveness of a dentifrice containing $8 \%$ arginine and calcium carbonate, diode laser (810 $\mathrm{nm})$ and combined use of diode laser $(810 \mathrm{~nm})$ and the same dentifrice in the treatment of dentinal hypersensitivity. It also compares the effectiveness of these three methods.

\section{Materials AND Methods}

This study was conducted in a laboratory setting in the Department of Prosthodontics, PMS College of Dental Science and Research,

() The Author(s). 2019 Open Access This article is distributed under the terms of the Creative Commons Attribution 4.0 International License (https://creativecommons. org/licenses/by-nc/4.0/), which permits unrestricted use, distribution, and non-commercial reproduction in any medium, provided you give appropriate credit to the original author(s) and the source, provide a link to the Creative Commons license, and indicate if changes were made. The Creative Commons Public Domain Dedication waiver (http://creativecommons.org/publicdomain/zero/1.0/) applies to the data made available in this article, unless otherwise stated. 
Thiruvananthapuram and in the SEM Lab, Sree Chitira Tirunal Institute of Medical Science and Technology, Thiruvananthapuram. Prior ethical clearance was obtained from the Institutional Ethics Committee, PMS College of Dental Science and Research, Golden Hills, Vattappara, Thiruvananthapuram (PMS/IEC/2012/04).

Forty dentin discs from extracted premolars free of caries used in the study were randomly allotted among the four groups given below. Teeth with cracked structures, carious lesions or restorations were excluded.

- Group A which was treated with desensitizing toothpaste only - Group B received treatment with GaAlAs diode laser $(810 \mathrm{~nm})$

- Group C treated with both GaAlAs diode laser $(810 \mathrm{~nm})$ and Desensitizing toothpaste

- Group D served as the control group

Briefly, the dentin discs were prepared to a thickness of $3 \mathrm{~mm}$ by cutting perpendicular to the long axis of the tooth using a low-speed diamond blade disc. ${ }^{32}$ The enamel was removed by a diamond disc at high speed under continuous water spray to prepare a dentin disc of average $6 \mathrm{~mm}$ diameter. The specimens were then rinsed with a hot water spraying apparatus for 30 seconds and ultrasonically cleaned for 1 hour. ${ }^{16}$ The specimens were then stored in phosphate buffer saline (PBS pH $=7){ }^{33}$

In group $A$, specimens were wetted with PBS buffer and thereafter dentifrice containing arginine and calcium carbonate was applied to the surface mixed with PBS and spread across the surface and left for 15 minutes at room temperature. The samples were then gently rinsed to ensure removal of the excess dentifrice. ${ }^{33}$ In group $B$, the specimens were subjected to diode laser $(810 \mathrm{~nm})$ irradiation at $1 \mathrm{~W}$ for $10 \mathrm{sec}$, totaling $10 \mathrm{~J}$ of energy, in continuous wave (CW), contact mode, using a non-initiated, $320 \mu$ tip, perpendicular to the surface, with scanning movements at 1 $\mathrm{mm} / \mathrm{second}$ (Energy density with movement $-305 \mathrm{~J} / \mathrm{cm}^{2}$ ). In group $C$, a dentifrice containing arginine and calcium carbonate was applied and specimens were subjected to diode-laser $(810 \mathrm{~nm})$ treatment. Group D was left untreated and served as the Control. All the specimens were then transported to the lab in PBS buffer.

The specimens were fixed in $4 \%$ glutaraldehyde solution buffered with sodium cacodylate $(\mathrm{pH}=7.4)$ for 18 hours. They were then dehydrated with a series of graded alcohol solutions. The samples were then covered in filter paper and subjected to critical

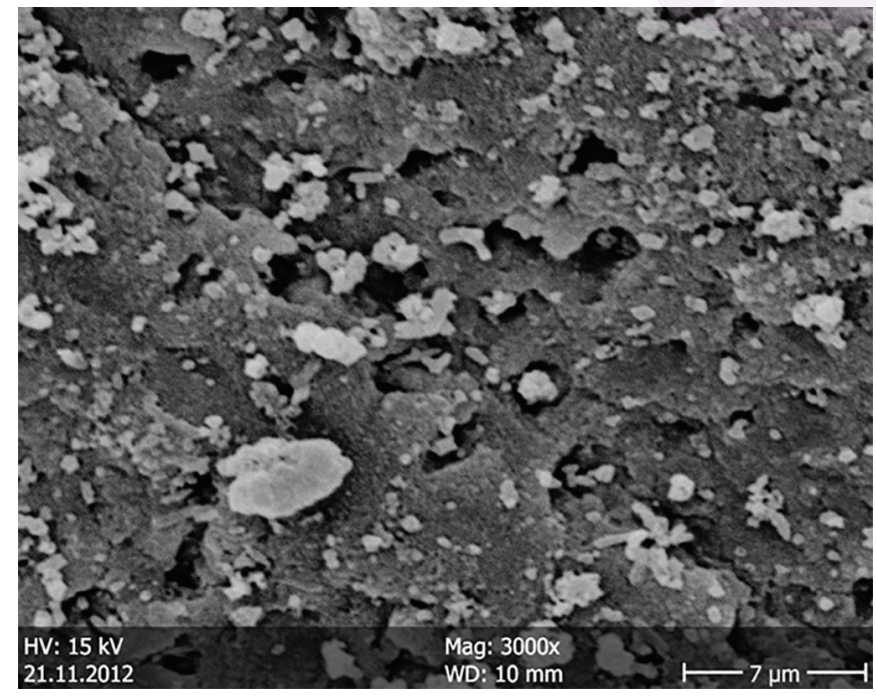

Fig. 1: SEM photomicrograph of the sample treated with desensitizing tooth paste point drying for 20 minutes in liquid $\mathrm{CO}_{2}$ and were sputter coated with gold in an ion sputtering device. The gold sputtered specimens were then placed in the vacuum chamber of the scanning electron microscope, and the dentinal tubule occlusion was evaluated by an experienced researcher who was blinded and unaware of the study groups per se, at $15 \mathrm{kV}$ and 3000x magnification. Then the photomicrographs of each specimen were taken (Figs 1 to 4) for analyzing the occlusion of dentinal tubules.

The diameters of the dentinal tubules of each specimen were evaluated and measured from the photomicrographs using rectangular marquee tool of CS7 software, by an examiner who was also blinded to the sample allotment according to the group, (double-blinded). A pixel-based measurement was obtained, and thereafter it was converted into microns using the scale provided in the SEM photomicrographs as:

- $7 \mu=209$ pixels

- 1 pixel $=7 \div 209 \mu$

- $x$ pixels $=x \times 7 / 209 \mu$

\section{Statistical Analysis}

The overall comparison between different treatment modalities was done using one way ANOVA. The multiple comparisons of different treatment modalities were done using post hoc Tukey HSD method. The entire test used was, and the $p$ value was fixed at $5 \%$. The data was tabulated on Microsoft Excel and analyzed using the software statistical package for social sciences (SPSS).

\section{Results}

In the overall comparison between different treatment modalities using One Way ANOVA (Table 1 and Graph 1) the mean diameters of dentinal tubules are:

- Group A: $1.12 \mu(S . D=0.13)$

- Group B: $0.51 \mu(S . D=0.095)$

- Group C: $0.28 \mu(S . D=0.055)$.

- Group D: $1.48 \mu(S . D=0.14)$ and $F=243.70$ with $p$ value of 0.0001 which revealed that there is a highly significant difference in the tubule diameter in different treatment modalities. The rate of occlusion of dentinal tubules (Table 2 ) is $24.32 \%$ in group A, $65.54 \%$ in group $B$ and $81.1 \%$ in group $C$ with the control value as the base value.

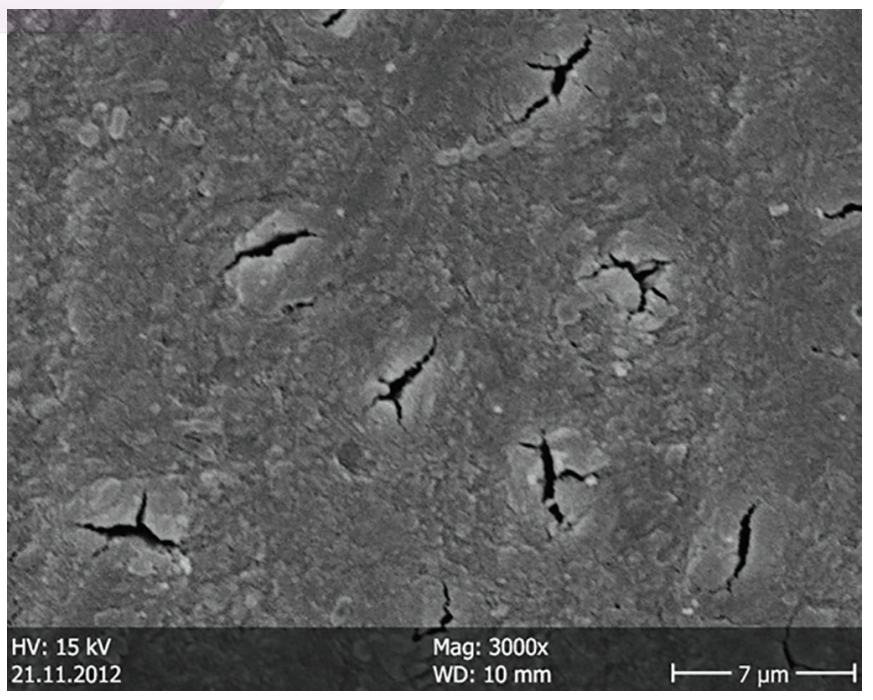

Fig. 2: SEM photomicrograph of the sample treated with diode laser $(810 \mathrm{~nm})$ 


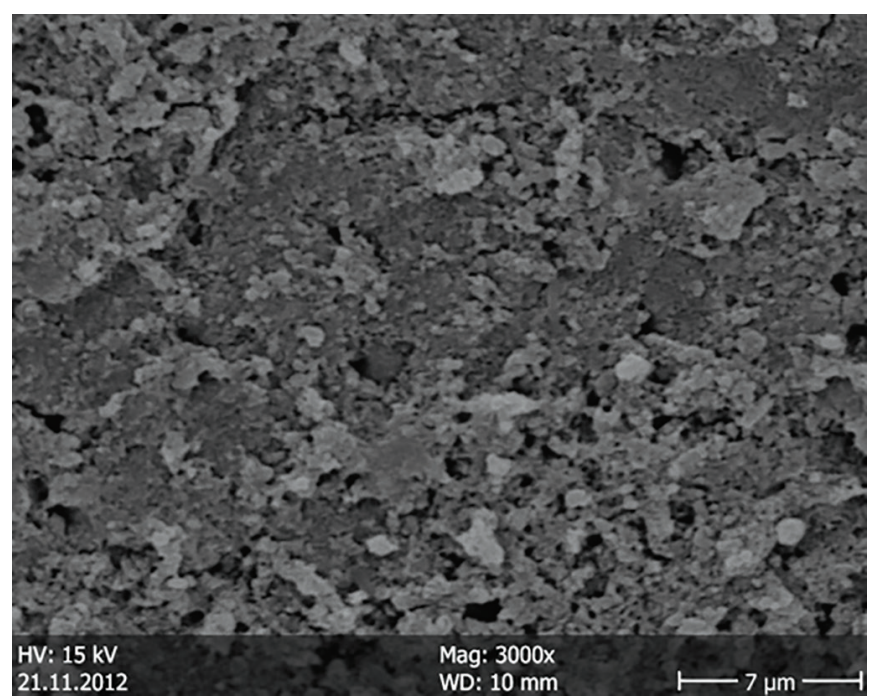

Fig. 3: SEM photomicrograph of the sample treated with diode laser $(810 \mathrm{~nm})+$ desensitizing tooth paste

Multiple comparisons using post-hoc Tukey HSD method (Table 3) showed that the mean difference of tubule diameters on comparing groups $A$ and $B$ is 0.61 ( $p$ value $=0.0001$ ) groups $A$ and $C$ is 0.84 ( $p$ value $=0.0001$ ); groups $A$ and $D$ is -0.36 ( $p$ value $=0.0001$ ); groups $B$ and $C$ is 0.23 ( $p$ value $=0.0001$ ) and group $C$ and $D$ is -1.2 ( $p$ value $=0.0001)$. In all comparisons, the $p$ values showed that the mean differences are statistically highly significant.

This showed that the combined use of desensitizing toothpaste and diode laser $(810 \mathrm{~nm})$ has the least tubule diameter suggesting that it is the best treatment modality in occluding dentinal tubules, the next better one is diode laser $(810 \mathrm{~nm})$ and finally the use of desensitizing toothpaste alone.

\section{Discussion}

Dentinal hypersensitivity has a multifactorial etiology, and generally, more than one factor is found to be associated and active in this painful manifestation. The most widely accepted theory of

Table 1: Overall comparison between different treatment modalities using one-way ANOVA

\begin{tabular}{llllll}
\hline & \multicolumn{3}{c}{$\begin{array}{c}\text { Tubule diameter } \\
\text { in microns }\end{array}$} & $\begin{array}{l}\text { Test } \\
\text { applied }\end{array}$ & \\
\cline { 2 - 5 } $\begin{array}{l}\text { Treatment } \\
\text { modality-test group }\end{array}$ & mean & median & S.D & ANOVA & p value \\
\hline $\begin{array}{l}\text { Tooth paste- } \\
\text { group A }\end{array}$ & 1.12 & 1.15 & 0.13 & & \\
& & & & & \\
Laser-group B & 0.51 & 0.50 & 0.095 & $\mathrm{~F}=243.70 \begin{array}{l}0.0001 \\
\text { highly } \\
\text { significant }\end{array}$ \\
$\begin{array}{l}\text { Tooth paste + laser } \\
\text { Group C }\end{array}$ & 0.28 & 0.27 & 0.055 & \\
Control-group D & 1.48 & 1.49 & 0.14 & & \\
\hline
\end{tabular}

\begin{tabular}{ll}
\multicolumn{2}{c}{ Table 2: Rate of occlusion of dentinal tubules } \\
\hline Group & Rate of occlusion \\
\hline Tooth paste-group A & {$[(1.48-1.12) \div 1.48] \times 100=24.32 \%$} \\
Laser-group B & {$[(1.48-0.51) \div 1.48] \times 100=65.54 \%$} \\
Tooth paste + laser group C & {$[(1.48-0.28) \div 1.48] \times 100=81.1 \%$} \\
\hline
\end{tabular}

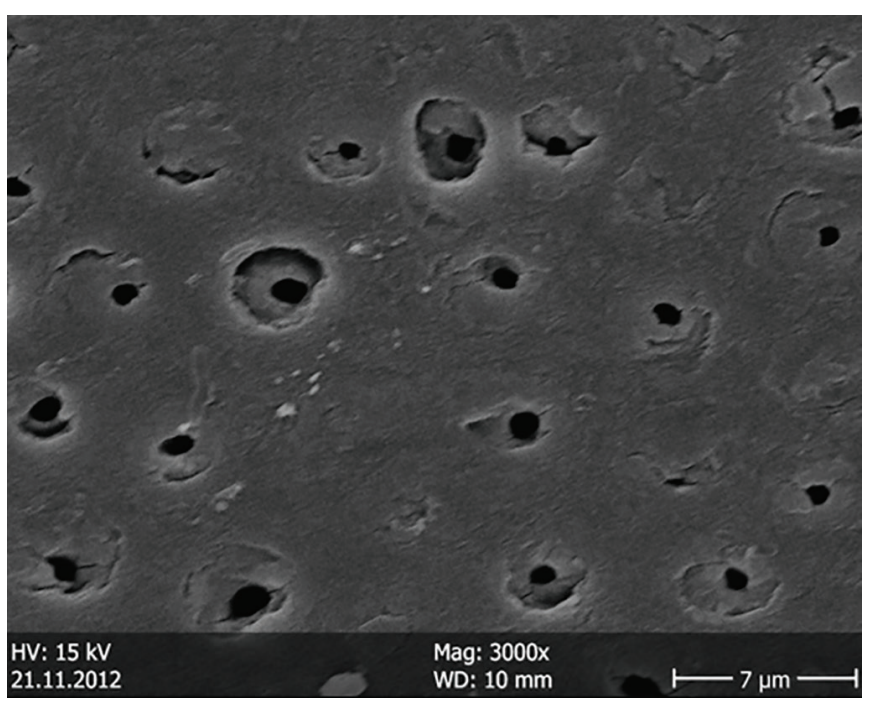

Fig. 4: SEM photomicrograph of the control sample

dentinal hypersensitivity is the hydrodynamic theory, which states that stimulus application induces pressure changes across dentin. As a result of the pressure changes, rapid shifts of fluids take place within the dentinal tubules, followed by the excitation of sensory

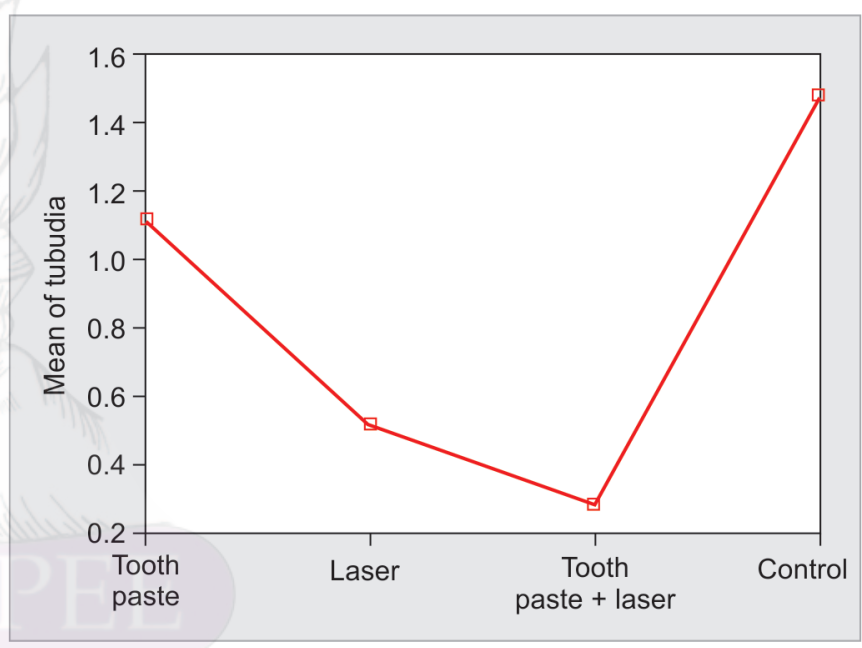

Graph 1: Line diagram showing overall comparison between different treatment modalities using one-way ANOVA

Table 3: Post-hoc Tukey comparison of different treatment modalities

\begin{tabular}{lll}
\hline Treatment modality-test group & $\begin{array}{l}\text { Tubule diameter } \\
\text { mean difference }\end{array}$ & p value \\
\hline $\begin{array}{l}\text { Tooth paste vs laser-group A VS } \\
\text { group B }\end{array}$ & 0.61 & 0.0001 \\
$\begin{array}{l}\text { Tooth paste vs tooth paste + laser } \\
\text { Group A vs group C }\end{array}$ & 0.84 & \\
$\begin{array}{l}\text { Tooth paste vs control - } \\
\text { Laser vs tooth paste + Laser }\end{array}$ & -0.36 & 0.0001 \\
Group B vs group C & & 0.0001 \\
$\begin{array}{l}\text { Laser vs control } \\
\text { Group B vs group D }\end{array}$ & 0.23 & 0.0001 \\
$\begin{array}{l}\text { Tooth paste + laser vs control } \\
\text { group C vs group D }\end{array}$ & -1.2 & \\
\hline
\end{tabular}


nerves in the pulp/ dentin border. Therefore, either physically blocking the exposed dentinal tubules or reducing the excitability of the relevant sensory nerves would effectively alleviate dentinal hypersensitivity. ${ }^{1,10,32}$

It is most commonly managed with the application of cavity varnishes, anti-inflammatory agents, tubular obturating procedures, or using dentine bonding agents and restorative resin.

Thus, as per the mechanism of action, the various treatment modalities for dentinal hypersensitivity include:

- Desensitization by blocking pulpal sensory nerves: It has been found that potassium ions $\left(\mathrm{K}^{+}\right)$in dentinal desensitizing preparations might act directly on intradental nerves by raising the concentration of $(\mathrm{K}+)$ in the extracellular fluids around these nerves sufficiently to prevent action potential generation through axonal accommodation. ${ }^{34}$

Desensitization by occluding the dentinal tubules and Desensitization by stimulation of the body's reparative mechanism by forming tertiary dentin.

Different noninvasive and reversible systems have been recommended for the treatment of this condition based upon their ability to occlude dentinal tubules. ${ }^{25}$

Lasers are found to have all three effects. Laser irradiation induces neural impairment including the slowing of conduction velocity (CV), decreasing compound action potential (CAP) amplitudes, suppression of response to noxious stimuli, suppression of pain-related neurotransmitters release, inhibition of enzyme activity, and morphological changes related to nerve conduction. ${ }^{35}$ Thermal and occlusive effects of certain lasers cause the sealing of exposed dentinal tubules through melting and recrystallization of dentin. ${ }^{32}$ Lee et al. in their study found that the dentin after Nd: YAG laser irradiation de monstrated a three-zone structure. The outer zone composed of hydroxyapatite and $\beta$ tricalcium phosphate showed an orderly columnar structure. The intermediate zone was a homogenous glass phase. The inner zone was with grain growth and well-crystallized prism. All three zones showed microstructure without pores and voids. Thus the energy output with $100 \mathrm{~mJ}-10$ pps-4 sec was found to reduce dentine permeability. ${ }^{36}$ Furthermore the treatment of dentinal hypersensitivity by the Diode laser revealed that the laser interaction with the dental pulp causes a photobiomodulating effect, increasing the cellular metabolic activity of the odontoblast and obliterating the dentinal tubules with the intensification of tertiary dentin production. ${ }^{1}$

This study embarked upon the probability of achieving tubule occlusion by using 3 different modalities namely using Desensitizing toothpaste containing arginine and calcium carbonate, a GaAlAs diode laser ( $810 \mathrm{~nm}, 1 \mathrm{~W}, 10 \mathrm{~J}, 10 \mathrm{sec}$ ) irradiation alone and desensitizing toothpaste used in conjunction with the diode laser. The tubule occlusion was evaluated by scanning electron microscopy (SEM). The results fully define that lasers (diode laser $810 \mathrm{~nm}$ ) has been an effective modality in conjunction with desensitizing toothpaste (mean tubule diameter $=0.28 \mu, p$ value $=$ 0.0001 ) and when used alone (mean tubule diameter $=0.51 \mu$, $p$ value $=0.00001$ ).

When compared to control samples (mean tubule diameter $=$ $1.48 \mu$ ) the desensitizing toothpaste could achieve only nearly $1 / 4$ th of tubule occlusion (mean tubule diameter $=1.12 \mu$, percentage occlusion $=24.32 \%$ ). On the other hand, in group B when Laser was used alone significant and effective closure of dentinal tubules up to $65.54 \%$ was achieved.

In comparison, when the diode laser $(810 \mathrm{~nm})$ was used in tandem with toothpaste, nearly complete occlusion of $81.1 \%$ was achieved. This proves that diode laser $(810 \mathrm{~nm})$ is an effective modality in the treatment of dentinal hypersensitivity through achieving tubule occlusion either when used alone or in conjunction with conventional methods.

When toothpaste was used alone there was only a marginal reduction (however significant reduction) in tubule diameter (24.3\%) when compared to the other two methods. In stark contrast to this, when the laser was used alone there was a nearly $1 / 3$ rd reduction in tubule diameter $(0.51 \mu)$ when compared to the control samples. And when diode laser was used in conjunction with toothpaste, there was nearly a $1 / 5$ th reduction in the tubule diameter $(0.28 \mu)$.

Dilsiz evaluated and clinically compared the efficacy of desensitizer toothpaste alone and in combination with diode (GaAlAs) laser (100 $\mathrm{mW}$ for 25 seconds at $808 \mathrm{~nm}$ ) in the management of dentin hypersensitivity. ${ }^{1}$ The immediate and late therapeutic effects of the diode laser were more evident compared with those of desensitizer toothpaste.

Lavender et al. ${ }^{33}$ Yingying Fu et al., ${ }^{22}$ Que et al. ${ }^{23}$ in their study showed that the treatment with the $8.0 \%$ arginine, a high cleaning calcium carbonate, and sodium monofluorophosphate dentifrice was highly effective in occluding dentin tubules which were confirmed by the present study. ${ }^{37-40}$

Lan et al. evaluated the combined occluding effect of sodium fluoride varnish and Nd.YAG laser irradiation on human dentinal tubules and found that over $90 \%$ of the dentinal tubule orifices were occluded. ${ }^{30}$

On the contrary, Gholami et al. in their study evaluating the occluding effects of Er.Cr.YSGG (P:0.25W,F:20Hz,Pd:140mS), Nd.YAG (P:1W, F:20Hz), CO2 (P:1W, Pd:50ms), and $810 \mathrm{~nm}$ Diode (P:2 W, Pd:30ms) lasers on dentinal tubules observed the highest reduction in mean tubule diameter with the Nd. YAG laser (53\%). ${ }^{41}$ Tubular diameter reduction in all laser groups $(p<0.05)$ was found to be statistically significant. However, Nd. YAG laser produces predominantly photothermal effects on teeth as compared to the Diode laser $(810 \mathrm{~nm})$ which has milder photothermal effects in comparison and can induce photochemical changes as well.

Sipahi et al. in their in vitro study demonstrated the dentinal tubule occluding effect of desensitizing laser (Er. Cr. YSGG Laser) treatment on dentin surfaces using environmental scanning electron microscopy (E-SEM).The tubule closure rates of 4 different irradiation modes were as follows: low potency/long time (74\%) > high potency/short time $(70 \%)>$ low potency/short time $(51 \%)>$ high potency/long time (46\%) > control (6\%). ${ }^{16}$ It was demonstrated that desensitizing laser application was an effective treatment option for the occlusion of dentinal tubule apertures. These findings [low potency/short time (51\%) and high potency/long time (46\%)] are consistent with those of the present study (51.1\%).

Pain and noxious stimuli are subjective responses that are highly variable from patient to patient according to the difference in pain threshold. Stimuli like thermal, tactile, osmotic, and electrical and exposure to air, can each elicit a sharp painful response in individuals with hypersensitive teeth. This paves the foundation for the different methods to measure dentinal hypersensitivity clinically. Tactile method ranges from the use of an explorer to devices that can quantify the probing pressure exerted usually along the cementoenamel junction. The thermal method involves the flow of air or metal probes applied in different ways. Electrical stimulus generally consists of progressive elevation of the magnitude of the stimulus until a sense of 'pre-pain' rather than pain is felt. Ideally, more than one method is needed in order to assess dentinal hypersensitivity. ${ }^{42}$ This study could evaluate it only from the viewpoint of tubule occlusion. A clinical and in vivo evaluation 
of the patient's comfort or pain could give a more complete picture of the effectiveness of such treatment modalities.

Moreover, diode lasers, if not used in optimal parameters, can induce irreversible and potentially damaging thermal effects on the tooth. While the parameters used in this study did not induce any such effects ${ }^{27}$ further investigation in this area is necessary. However, within such limitations, this study has undoubtedly established the effectiveness of diode laser $(810 \mathrm{~nm})$ when used alone or in combination with a desensitizing toothpaste containing arginine and calcium carbonate in the treatment of dentinal hypersensitivity.

\section{Conclusion}

Lasers are an effective modality in treating dentinal hypersensitivity by effecting tubule occlusion.

Desensitizing toothpaste containing $8 \%$ arginine and calcium carbonate has been found to significantly occlude dentinal tubules, but when used in conjunction with a diode laser $(810 \mathrm{~nm})$ it has been found to be the most effective.

Lasers have been found to be more effective in occluding dentinal tubules when used as a standalone modality even more than when the desensitizing toothpaste was used alone.

\section{Clinical significance}

This study suggests an effective treatment of dentinal hypersensitivity using Diode Laser and desensitizing toothpaste.

This study is a thesis dissertation document submitted in fulfillment of Master of Dental Surgery (MDS) degree to the Kerala University of Health Sciences.

\section{References}

1. Dilsiz A, Aydın T, Emrem G. Effects of the Combined Desensitizing Dentifrice and Diode Laser Therapy in the Treatment of Desensitization of Teeth with Gingival Recession. Photomed Laser Surg 2010;28:Supplement 2.

2. Gillam DG, Bulman JS, Eijkman MAJ, et al. Dentists' perceptions of dentine hypersensitivity and knowledge of its treatment. J Oral Rehab 2002;29;219-225.

3. Rees JS, Addy M. A cross-sectional study of dentine hypersensitivity. J Clin Periodontol 2002;29:997-1003.

4. Rosenstiel SF, Rashid RG. Postcementation Hypersensitivity: Scientific Data Versus Dentists' Perceptions. J Prosthodont 2003:12(2):73.

5. Cummins $D$. Recent advances in dentin hypersensitivity: Clinically proven treatments for instant and lasting sensitivity relief. Am J Dent 2010;23Sp Is A:3A-13A.

6. Mausner IK, Goldstein GR, Georgescu M. Effect of two dentinal desensitizing agents on retention complete cast coping using four cements. J Prosthet Dent 1996;129-134.

7. Yim NH, Rueggeberg FA, Caughman WF, et al. Effect of dentin desensitizers and cementing agents on retention of fullcrowns using standardized crown preparations. J Prosthet Dent 2000;83:459-465.

8. Cuenin MF, Scheidt MJ, O'Neal RB, et al. Horner and Thomas E. Van Dyke. An In vitro Study of Dentin Sensitivity and the Patency of Dentin Tubules. J Periodontol 1991;62:668-673.

9. Yoshiyama M, Masada J, Uchida A, et al. Scanning Electron Microscopic Characterization of Sensitive vs. Insensitive Human Radicular Dentin. J Dent Res 1989.68(11):1498-1502.

10. Wylie SG, Wilson PR. An Investigation into the Pressure Transmitted to the Pulp Chamber on Crown Cementation : A Laboratory Study. J Dent Res 1994.73(11):1684-1689.

11. Absi E G, Addy M, Adams D. Dentin hypersensitivity. A study of the patency of dentinal tubules in sensitive and non sensitive cervical dentin. J Clin Periodontol 1987;14:280-284.

12. Porto IC, Andrade AK, Montes MA. Diagnosis and Treatment of Dentinal Hypersensitivity. J Oral Sci 2009; 51(3):323-332.
13. Markowitz K, Pashley DH. Discovering new treatments for sensitive teeth: the long path from biology to therapy. J Oral Rehab 2008;35:300-315.

14. Sipahi C, Cehreli M, Ozen J, et al. Effects of precementation desensitizing laser treatment and conventional desensitizing agents on crown retention. Int J Prosthodont 2007;20(3):289-292.

15. Abdulhamaid A. Maghrabi. Effect of Dentin Sealers on Postoperative Sensitivity of Complete Cast Crowns Cemented with Glass lonomer Cement. J Prosthodont 2011;20:385-390.

16. Sipahi C, Berk N, Ozen J, et al. Tubule-Occluding Effect of Desensitizing Laser Treatment on Prepared Dentin Surfaces: An Environmental SEM Study. Int J Prosthodont 2006;19:37-39.

17. Kishore A, Mehrotra KK, Saimbi CS. Effectiveness of Desensitizing Agents. Journal of Endodontics 2002;28(1):34-35.

18. Ling TY, Gillam DG, Barber PM, et al. An investigation of potential desensitizing agents in the dentine disc model: a scanning electron microscopy study. J Oral Rehab 1997;24;191-203.

19. Wolfart S, Wegner SM, Kern M. Comparison of using calcium hydroxide or a dentine primer for reducing dentinal pain following crown preparation: a randomized clinical trial with an observation time up to 30 months. Journal of Oral Rehabilitation 2004 31; 344-350.

20. Ajcharanukul $O$, Kraivaphan $P$, Wanachantararak $S$, et al. Effects of potassium ions on dentine sensitivity in man. Arch Oral Biol 2007;52:632-639.

21. Wara-aswapati N, Krongnawakul D, Jiraviboon D, et al. The effect of a new toothpaste containing potassium nitrate and triclosan on gingival health, plaque formation and dentine hypersensitivity. J Clin. Periodontol 2005;32:53-58.

22. Fu Y, Li X, Que K, Wang M, et al. Instant dentin hypersensitivity relief of a new desensitizing dentifrice containing $8.0 \%$ arginine, a high cleaning calcium carbonate system and 1450 ppm fluoride: A 3-day clinical study in Chengdu, China. Am J Dent 2010;23 Sp Is A:20A-27A.

23. Que $K, F u Y$, Lin $L$, et al. Dentin hypersensitivity reduction of a new toothpaste containing 8.0\% arginine and 1450 ppm fluoride: An 8-week clinical study on Chinese adults. Am J Dent 2010;23 Sp Is A:28A-35A .

24. Kimura $Y$, Wilder-Smith $P$, Yonaga $K$, et al. Treatment of dentine hypersensitivity by lasers: a review.J Clin Periodontol 2000;27: 715-721.

25 Hong L, Wu M, Zhang C. Using Nd-YAG laser to desensitize the hypersensitive dentine in preparing the abutment teeth for removable partial dentures prosthesis. Chinese J Stomatol 1997;32(1):28-30.

26. Zhang $\mathrm{C}$, Matsumoto $\mathrm{K}$, Kimura $\mathrm{Y}$, et al. Effects of $\mathrm{CO}_{2}$ laser in the treatment of cervical dentinal hypersensitivity. J Endodont 1998;24(9):595-597.

27. Arrastia AM, Machida T, Smith PW, et al. Comparative study of the thermal effects of four semiconductor lasers on the enamel and pulp chamber of a human tooth. Lasers Surg Med 1994;15:382-389.

28. de Souza MR, Watanabe IS, Azevedo LH, et al. Morphological alterations of the surfaces of enamel and dentin of deciduous teeth irradiated with Nd:YAG, CO2 and diode lasers. Int J Morphol 2009; 27(2):441-446.

29. Badran Z, Boutigny H, Struillou X, et al. Tooth desensitization with an Er:YAG laser: in vitro microscopical observation and a case report. Lasers Med Sci 2011;26:139-142.

30. Lan WH, Liu HC, Lin CP. The Combined Occluding Effect of Sodium Fluoride Varnish and Nd:YAG Laser Irradiation on Human Dentinal Tubules. J Endodont 1999;25(6).

31. Schwarz F, Arweiler N, Georg T, et al. Desensitizing effects of an Er:YAG laser on hypersensitive dentine. A controlled, prospective clinical study. J Clin Periodontol 2002;29:211-215.

32. Lee BS, Chang CW, Chen WP, et al. In vitro study of dentin hypersensitivity treated by Nd- YAP Laser and Bioglass. Dent Mater 2005;21:511-519.

33. Lavender SA, Petrou I, Heu R, et al. Mode of action studies on a new desensitizing dentifrice containing $8.0 \%$ arginine, a high cleaning calcium carbonate system and 1450 ppm fluoride. Am J Dent 2010;23Sp Is A:14A-19A.

34. Peacock JM, Orchardson R. Effects of Potassium lons on Action Potential Conduction in A- and C-Fibersof Rat Spinal Nerves. J Dent Res 1995;74(2):634-641. 
35. Chow R, Armati P, LiisaLaakso E, et al. Inhibitory Effects of Laser Irradiation on Peripheral Mammalian Nerves and Relevance to Analgesic Effects: A Systematic Review. Photomed Laser Surg 2011;10(10):1-17.

36. Lee BS, Lin CP, Lin FH, et al. Ultra structural Changes of Human Dentin after Irradiation by Nd:YAG laser. Laser Surg Med 2002;30:246-252.

37. Sicilia A, Cuesta-Frechoso S, Suárez A, et al. Immediate efficacy ofdiode laser application in the treatment of dentine hypersensitivity in periodontal maintenance patients: a randomized clinical trial. J Clin Periodontol 2009;36:650-660.

38. Pesevska S, Nakova M, Ivanovski K, et al. Dentinal hypersensitivity following scaling and root planing: comparison of low-level laser and topical fluoride treatment. Lasers Med Sci 2009;Jun 1.
39 Marsilio AL, Rodrigues JR, Borges AB. Effect of the clinical application of the GaAlAs laser in the treatment of dentine hypersensitivity. J Clin Laser Med Surg 2003;21:291-296.

40. Johnson GH, Lepe $X$, Bales DJ. Crown retention with use of a $5 \%$ glutaraldehyde sealer on prepared dentin. J Prosthet Dent 1998;79:671-676.

41. Gholami GA, Fekrazad R, Esmaiel-Nejad A, et al. An Evaluation of the Occluding Effects of Er;Cr:YSGG, Nd:YAG, $\mathrm{CO}_{2}$ and Diode Lasers on Dentinal Tubules: A Scanning Electron Microscope In Vitro Study. Photomed Laser Surg 2011; 29(2): 115-121.

42. Kleinberg I, Kaufman HW, Confessore F. Methods of measuring tooth hypersensitivity. Dent Clin North Am. 1990;34(3):515-529. 